\title{
Editorial
}

\section{Eating for Two?}

Yes, pregnant women are eating for two, but the equation is not as simple as the statement suggests. Hormonal changes in the mother drive a number of metabolic and physiological processes that are designed to support the development and growth of the fetus, without undue burden on the mother. As a result the increased nutrient requirements of pregnancy are not simply the sum of those accumulated by the fetus, the placenta and by maternal tissues. Rather, hormonal changes are designed to increase the delivery of nutrition to the fetus such that the actual energy requirement during the first trimester of pregnancy is not increased from the nonpregnant state and maternal energy intake in the second and third trimesters only requires an increase in energy intake by about $10 \%$. However, in cases where the nutritional fuel is insufficient or in excess, metabolic and physiological adaptations result and these adaptations often have longlasting consequences.

A relevant and contemporary example in which the depletion of a specific nutrient during early pregnancy causes permanent long-term consequences is that of folate and neural tube defects (NTDs). NTDs are congenital malformations which arise during the development of the brain and spinal cord. A band of cells along the dorsal surface of the embryo develops into a groove and then a hollow tube. The process is completed within a month of fertilization (by the 6th week after the last menstrual period). Incomplete closure of the neural tube causes NTDs. Exactly why NTDs happen is not entirely clear, although both environmental and genetic factors are considered important, including the role of folate in ameliorating the effects of disturbed homocysteine metabolism. The Cochrane systematic review on the topic [1] has summarized the results of 4 trials involving 6,425 women and showed that preconception folate supplementation reduced the incidence of NTDs by $72 \%$ (relative risk $=0.28,95 \%$ confidence interval $=0.13-0.58$ ), clearly highlighting the strong protective effect of folate supplementation and the rationale of the public health recommendation for universal periconceptional supplementation for all women.

This issue of Annales Nestlé is dedicated to motherchild nutrition and has a particular focus on pregnancy nutrition with 3 papers that highlight the importance of balanced nutrition in both industrialized and semi-industrialized environments.

The first, by Professor Cetin and Dr Cardellicchio from the Mother and Child Hospital Luigi Sacco and University of Milan, provides an instructive overview of metabolic interplay between the mother, the placenta and the fetus, and how changes in the equilibrium between mother, placenta and fetus can compromise the pregnancy outcome. Clearly maternal diet is an important environmental factor, but it is not the only one. Maternal body composition, maternal hormonal adaptations, the quality and function of the placenta and even the fetus through its unique genetic makeup and endocrine environment all contribute to the quality of the pregnancy outcome.

The second chapter by Dr Herring, Temple University Philadelphia, and Dr Oken, Harvard Medical School, strongly complements the first with a detailed review of

\begin{tabular}{|c|c|}
\hline KARGER & $\begin{array}{l}\text { (C) } 2010 \text { Nestec Ltd., Vevey/S. Karger AG, Basel } \\
0517-8606 / 10 / 0681-0005 \$ 26.00 / 0\end{array}$ \\
\hline $\begin{array}{l}\text { Fax +41 } 613061234 \\
\text { E-Mail karger@karger.ch } \\
\text { www.karger.com }\end{array}$ & $\begin{array}{l}\text { Accessible online at: } \\
\text { www.karger.com/ane }\end{array}$ \\
\hline
\end{tabular}


the influences of gestational weight gain on both maternal and child outcomes. The chapter summarizes the clinical and epidemiological evidence linking gestational weight gain with glucose metabolism, hypertensive disorders, complications at birth, postpartum weight retention, maternal obesity risk and the associated cardiometabolic sequelae, as well as fetal growth, preterm birth and infant mortality, and longer-term weight and obesity risk in the offspring. The chapter has important messages for both industrialized and semi-industrialized countries as both low and high gestational weight gains are associated with negative outcomes. Herring and Oken end with an excellent state-of-the-art summary of the gestational weight gain targets for women entering pregnancy with low, normal and high body mass indices.

The final chapter by Dr Usha Ramakrishnan from Emory University, Atlanta, provides a critical review of the effectiveness of prenatal nutrient supplements in improving maternal and child health outcomes. The range of supplements reviewed includes iron and folic acid, multiple micronutrients, calcium, magnesium, iodine, vitamin $\mathrm{A}$, zinc, vitamin $\mathrm{D}$, antioxidants, $\omega-3$ long-chain polyunsaturated fatty acids and probiotics. The theme regarding the different needs of women from industrialized and semi-industrialized communities recurs. This time the benefit of multiple micronutrient supplements and minerals such as calcium and zinc during pregnancy for at-risk populations is shown to promote the health and well-being of mothers and their offspring in a cost-effective manner.

This issue of Annales Nestlé has not dealt with nutrition during lactation, where the delivery of nutrients is optimized through breast milk; this could be a topic for a later issue.

\author{
Olle Hernell, Umeå \\ Michael Lentze, Bonn \\ Maria Makrides, Adelaide \\ Frank Ruemmele, Paris \\ Noel Solomons, Guatemala City \\ Hania Szajewska, Warsaw
}

